\title{
Predictors of Low Birth Weight in Newborn Delivered in Public Hospital of Gurage Zone, Southern Ethiopia: A Case-Control Study
}

\author{
Andamlak Dendir Egata1, Temesgen Abera Bafa ${ }^{2}$ \\ ${ }^{1}$ Public Health Department, College of Medicine and Health Sciences, Wolkite University, Wolkite, Ethiopia \\ ${ }^{2}$ Medical Laboratory Department, College of Medicine and Health Sciences, Wolkite University, Wolkite, Ethiopia \\ Email: andamlakdendir@gmail.com
}

How to cite this paper: Egata, A.D. and Bafa, T.A. (2019) Predictors of Low Birth Weight in Newborn Delivered in Public Hospital of Gurage Zone, Southern Ethiopia: A Case-Control Study. Food and Nutrition Sciences, 10, 428-438. https://doi.org/10.4236/fns.2019.104032

Received: February 8, 2019

Accepted: April 21, 2019

Published: April 24, 2019

Copyright $\odot 2019$ by author(s) and Scientific Research Publishing Inc. This work is licensed under the Creative Commons Attribution International License (CC BY 4.0).

http://creativecommons.org/licenses/by/4.0/ (c) (i) Open Access

\begin{abstract}
Worldwide, low birth weight is one of the most common causes of neonatal morbidity and mortality. Though factors associated with low birth weight vary from one region to another, in Gurage Zone, there is no sound analytical study done to examine the local determinants of low birth weight. Because of this, the study aimed to elucidate the predictors of low birth weight in public hospital of Gurage zone. Methods: A facility based unmatched case-control study design was employed to detect the existing exposure difference between cases and controls. The study included a total of 270 controls (normal weight) and 134 cases (low birth weight baby). Control and case participants were selected through consecutively. To collect the data, structured interviewer administered questionnaires and anthropometric measurement were used. The data were entered through Epi-data 3.1 computer program and analyzed through Statistical package for Social Sciences version 21 (SPSS v. 21). Univariate, Bivariate and Multivariate analysis were done. Result: Multiple logistic regression model analysis indicated that low birth weight was independently associated with maternal mid upper arm circumference less than $23 \mathrm{~cm}$ (AOR $1.79(95 \% \mathrm{CI}=1.01-3.16)$ ), gestational age less than 37 weeks (AOR 24.94 $(95 \% \mathrm{CI}=12.38-50.27)$ ), presence of malaria infection during period of pregnancy (AOR $3.02(95 \% \mathrm{CI}=1.39-6.51)$ ), presence of preclampsia, multiparity (AOR $2.19(95 \% \mathrm{CI}=1.21-3.96))$ and twining (AOR $5.4295 \% \mathrm{CI}=$ 2.01 - 14.59). Conclusion: Gestational age $<37$ weeks, twining, malaria infection during pregnancy and maternal undernutrition were a significant predictor of LBW in the region of Gurage zone. Hence, to effectively prevent low birth weight, Gurage zone health departments should work on promotion of maternal nutrition during pregnancy, prevention of malaria during pregnancy.
\end{abstract}




\section{Keywords}

Predictors of Low Birth Weight, Determinants of Low Birth Weight, Factor Affecting Low Birth Weight

\section{Introduction}

World Health Organization (WHO) defined low birth weight as birth weight of less than 2500 grams (5.5 pounds). The period of intrauterine growth and development is one of the most vulnerable periods in the human lifecycle [1]. The weight of an infant at birth is an important predictor of infant growth and survival. Infants born with low birth weight (LBW) are highly vulnerable for childhood infection and under nutrition which have high rates of morbidity and mortality [2]. Moreover, evidence now shows that infants born with LBW face an increased risk of chronic diseases including high blood pressure, non-insulin dependent diabetes mellitus, coronary heart disease and stroke in adulthood [3]. Low birth weight is an intergenerational problem where low birth weight infants grow up to be undernourished adolescents and, ultimately, undernourished women of childbearing age, and undernourished pregnant women who deliver low birth weight infants. This amplifies risks to the individual's health and perpetuates the cycle of poverty, under nutrition and disease. This is especially so when adolescents become pregnant before their own growth is completed, leaving little to fulfill their own or their infant's nutritional requirements. Prematurity and intrauterine growth retardations are the two general causes of low birth weight. The majority of low birth weight in developing countries is due to intrauterine growth retardation, while most low birth weight in industrialized countries is due to preterm birth [4]-[9].

Worldwide, low birth weight is one of the most common causes of neonatal morbidity and mortality. Globally, more than 20 million infants, representing about $15 \%$ - $20 \%$ of all births, were born with low birth weight every year. Even if, the burden of low birth weight is varied cross countries to countries and region to region, the majority of low birth weight births occur in low- and middle-income countries and especially in the most vulnerable populations [10] [11]. Regional estimates of LBW indicated that 34\% in Asia, 38\% in Africa, 9\% in Latin America, 13\% in least developed countries [12]. Overall, developing countries especially Asia and Africa account 96.5 percent of the estimation.

In-depth analyses of the Ethiopian Demographic and Health Survey of 2011 showed that $29.3 \%$ of new born in Ethiopia were low birth weight, indicating a major public health problem of the country. Looking out the policy, WHO shows it policy commitment through endorsing the problem in comprehensive implementation plan on maternal, infant and young child nutrition, which specified six global nutrition targets for 2025 [12]. The policy covers the issue of the 
low birth weight and sets a 30\% reduction of low birth weight in 2025 in its third target. Through considering the global target [12], the government of Ethiopia also incorporates the issue of low birth weight reduction in its five-year growth and transformation plan II.

Reviewing the determinants of low birth weight, Low birth weight is a complex syndrome which can be caused by prematurity, IUGR (intrauterine growth retardation) or can be caused by through both factors. It has long been recognized maternal age, maternal nutritional status, access to antenatal care, presence of heavy work load, smoking, and parental educational status, gestational age, congenital anomalies, presence of pregnancy related illness, maternal stature and, pregnancy weight gain as a determinant of LBW [13]-[18]. However, the relative importance of each of the known risk factor of LBW is varying from country to country, region to region and place. That is why, this study aimed to assess the local determinants of low birth weight particularly in Gurage Zone.

\section{Methods and Materials}

\subsection{Study Area and Period}

The study was conducted in Atat, Butajira General Hospital, Sodo and Gunchire Hospital of Gurage zone. Butajira hospital, which is located $135 \mathrm{~km}$ south of Addis Ababa and $50 \mathrm{~km}$ to the west of Zeway town, is the zonal hospital of Gurage zone and constitutes a total of 144 beds and five major wards like pediatric, gynecology, obstetric, surgery, and medical wards and one therapeutic feeding center. Similar to Butajira hospital, Atat hospital is a private owned hospital and it has been offering different health care service and it has been giving different exemption service similar to the one implemented by any public hospital. Sodo and Gunchire hospitals are district hospital located in Sodo and Enamor districts of the zone and they also have been offering different health care service including delivery care service. The data for the study was collected during period of November 30, 2016 to march 30, 2017.

\subsection{Study Design and Population}

Facility based unmatched case - control study design was applied to detect the existing exposure difference between cases and controls. Cases were those new born who had birth weight of $<2500 \mathrm{~g}$ within one hour of their birth and controls were those new born with birth weight of $\geq 2500$ g one hour of their birth. All eligible newborns delivered in Butajira and Atat Hospital during study period was considered as a study population.

\subsection{Inclusion Criteria and Exclusion Criteria}

All live births from mothers who have lived in Gurage zone at least for six month were included in the study. However those case and controls that lost their mother during their birth were excluded from the study. 


\subsection{Sample Size Determination}

To determine the total sample size, two population proportion formulas for unmatched case control were applied in statistical program of Epi-info version 7. Three major exposure variables: maternal age group, birth interval and maternal MUAC were considered for sample size calculation. The same statistical assumptions were assumed for all variables. The assumptions were: $-95 \%$ Confidence level, Power of $80 \%$, Case to Control ratio of 1:2, detecting 2.01 times difference in exposure among cases and the proportion of mother who have age less than $20 \mathrm{yr}$ among controls groups is $21.7 \%$ and non response rate of $5 \%$. Finally, the total sample size determined to investigate the existing exposure difference between cases and controls was 135 cases and 270 controls.

\subsection{Sampling Technique and Procedures}

Since there was no sufficient numbers of cases during study period, all cases and control were selected/consecutively without living any interval if they are eligible for the study.

\subsection{Study Variables}

Maternal stature, Maternal age, parity, birth interval, Maternal education level, Maternal occupation, Maternal nutritional status, history of anemia, History of diagnosed Malaria during current pregnancy, history of preeclampsia during current pregnancy, history of eclampsia during current pregnancy, History of ante partum hemorrhage (APH), Smoking, Antenatal care (ANC) visit, twinning, presence of congenital anomalies, placenta abnormality, prematurity, sex of child, Paternal occupation, paternal educational level, Marital status, Religion, ethnicity, residence were the independent variables of the study where as low birth weight were the dependent variable of the study. In this study low birth weight (cases) defined as a birth weight less than $2500 \mathrm{~g}$. Where as normal weight (controls) means a birth weight greater than or equal to $2500 \mathrm{~g}$. Premature birth is a birth before 37 weeks of gestation. A mother who don't have servant or home assistant or if she reported absence of work share from their husband they categorized as having heavy home work load.

\subsection{Data Collection Procedures and Techniques}

Structured and interviewer administered questionnaires which was adapted from literature was used. It was consist of questions that could measure maternal associated factor, socio-demographic and fetal associated factors. Since it was written in English version, it was translated in to Amharic version for common understanding. Prestige scale was used to measure the weight and height of mother. Weight was measured in undressed or with minimum clothing and the weighting scales was calibrated with known weight object regularly. The scales indicator was checked against zero reading after weighing every child and mother. By basing previous experience on data collection activity and supervi- 
sion, diploma nurses/midwifes and health officer was recruited from all hospital of Gurage Zone.

\subsection{Data Quality Management}

The sample of questionnaire was pre-tested on population out of study area and later, necessary modification was taken. To assure the quality of data Intensive two day training was given for both the data collectors and supervisor. During period of data collection close supervision was done by supervisor and authors.

\subsection{Ethical Considerations}

Since the study procedure didn't undergone immoral and invasive procedures, letter of permission were obtained from the research ethics committee of Wolkite University. Cooperation letter to district health office was gained from $\mathrm{Gu}$ rage Zone health bureau. Verbal data were obtained from the participants mothers. After the mother got clear explanation on the objective, risk and benefit of the research work their verbal consent was obtained.

\section{Data Analysis}

To minimize data entry error, the collected data was entered into EPI data 3.1 computer programs and exported to Statistical Package for Social Sciences version 21 for cleaning, recoding, categorizing and analyzing. Descriptive statistics like mean, frequency and percentage was calculated. To evaluate the association between a single independent variable with dependent variable crude odds ratio was used and those variable with p-value of less than 0.05 was included in the advanced model of analysis. Since the outcome variable is categorical type, adjusted odds ratio was calculated through binomial multiple logistic regressions model. Model fitness was checked by Hosmer and Leme show goodness of fit test and later $95 \%$ CI was used to test statistical significance of the association between dependent and independent variables.

\section{Results}

A total of 404 newborn-mother pairs ( 135 cases and 270 controls) were planned to be studied in the project but for various reason only 131 cases and 265 controls were delightful for invitation, which give us the overall response rate of 97.7\%.

\subsection{Socio-Demographic Characteristic}

Of those children who were included in the analysis, fort eight (48) percent of cases were Muslim where as 48.8 percent of controls were orthodox by religion. While the majority of controls were from rural area (75.3\%), more than fifty percent of cases were from urban area (55\%). The majority of mothers in both cases (64\%) and controls (68\%) had formal education. Regarding paternal education 101 (77.1\%) of cases and 197 (94.1\%) of controls were had father who had 
formal education. pertaining to maternal occupation only $20(15.5 \%)$ of cases and $30(11.6 \%)$ of controls were working as an employee in governmental and nongovernmental organization (Table 1).

\subsection{New Born Characteristics}

Almost equal proportions of children in both cases (53\%) and controls (60\%) were male. 54\% of cases were gestational age less than 37 weeks and only $5 \%$ of controls were gestational age less than 37 Weeks. Regarding multiple pregnancy $17 \%$ of case and $6 \%$ of controls were twin. Pertaining to presence of congenital and placental anomalies all study subjects were frees of congenital anomalies and placental abnormality. Looking at the birth interval of the participants, about

Table 1. Socio-demographic table characteristics of the mothers by the new born birth weight in Gurage zone public hospital, June 2017.

\begin{tabular}{|c|c|c|c|}
\hline Explanatory Variables & Category & Case & Control \\
\hline \multirow{3}{*}{ Maternal Age Group } & $<18 \mathrm{yrs}$ & 1 & 7 \\
\hline & $18-35 \mathrm{yrs}$ & 119 & 239 \\
\hline & $>35 \mathrm{yrs}$ & 11 & 11 \\
\hline \multirow{4}{*}{ Religion } & ortodox & 63 & 133 \\
\hline & catholic & 9 & 11 \\
\hline & protestant & 13 & 32 \\
\hline & Muslim & 46 & 89 \\
\hline \multirow{4}{*}{ Maternal Occupation } & employee & 20 & 31 \\
\hline & Farmer & 15 & 27 \\
\hline & Merchant & 11 & 24 \\
\hline & housewife & 85 & 183 \\
\hline \multirow{3}{*}{ Maternal Educational Status } & Had formal education & 90 & 170 \\
\hline & Had no formal education & 41 & 95 \\
\hline & Primary & 61 & 100 \\
\hline \multirow{3}{*}{ Maternal Level of Education } & Secondary & 7 & 45 \\
\hline & Diploma & 9 & 12 \\
\hline & Degree and above & 13 & 13 \\
\hline \multirow{3}{*}{ Paternal Educational Status } & Had formal education & 101 & 197 \\
\hline & Had no formal education & 30 & 67 \\
\hline & Primary & 46 & 103 \\
\hline \multirow{3}{*}{ Paternal Level of Education } & Secondary & 26 & 55 \\
\hline & Diploma & 9 & 10 \\
\hline & Degree and above & 20 & 29 \\
\hline \multirow{4}{*}{ Paternal Occupation } & Employee & 38 & 56 \\
\hline & Farmer & 70 & 137 \\
\hline & Merchant & 13 & 51 \\
\hline & Other & 10 & 20 \\
\hline
\end{tabular}


seventy six (76.7\%) of cases and about forty five percent $(45.8 \%)$ of controls (23.7\%) had birth interval of greater than or equal to 2 years (Table 2 ).

\subsection{Obstetrics Characteristics}

Out of 131 case mothers and 265 controls mother almost 77\% of mothers in both group had ANC follow during their pregnancy. Regarding pregnancy related complication all controls had no history of pre eclampsia. ecalmpsia and APH where as only six cases participant had history of pre-eclampsia, elampsia and APH. More than 50 percent of case and controls were multipara (Table 3 ).

\subsection{Logistic Regression Analysis on Factors Associated With Low Birth Weight}

After adjusting for potential confounder through multivariate logistics regress in maternal less than $23 \mathrm{~cm}$, gestational age less than 37 weeks, presence of malaria infection during period of pregnancy, multiparty and twining were significantly associated with low birth weight.

Gestational age less than 37 week was strongly associated with LBW. Those newborn born before 37 week of gestation had about 24 times higher risk of LBW (AOR 24.94 (95\% CI = 12.38 - 50.27)]. The risk of having a new born with LBW among mothers who experienced malaria infection during their pregnancy period is about three fould compared to malaria free mothers (AOR 3.02 (95\% $\mathrm{CI}=1.39$ - 6.51). In this study another strong predictor of low birth weight was being a twin. Compared to singleton baby twins had 5.4 times higher risk of low birth weight (AOR $5.4295 \% \mathrm{CI}=2.01$ - 14.59). Of obstetrics characteristics of mother that showed a significant association is parity. The odds of LBW among Multipara mothers were about two times higher than unipara mother (AOR 2.19

Table 2. Characteristics of the new born by their birth weight in in Gurage zone Public Hospital, Gurage Zone, SNNPR, June, 2015.

\begin{tabular}{cccc}
\hline Explanatory Variables & Category & Case & Control \\
\hline \multirow{2}{*}{ Gestational Age } & $<37$ weeks & 74 & 14 \\
Twining & $\geq 37$ weeks & 57 & 251 \\
& Twin & 23 & 9 \\
Congenital Anomalies & Present & 108 & 254 \\
& Absent & 1 & 1 \\
Placental Abnormality & Present & 130 & 262 \\
Sex & Absent & 0 & 0 \\
Birth Interval & Male & 131 & 263 \\
& Female & 68 & 159 \\
& $<2$ yrs & 63 & 105 \\
& $\geq 2$ yrs & 43 & 71 \\
\hline
\end{tabular}


Table 3. Obstetrics characteristics of study participant's mother, southern Ethiopia, Gurage zone 2017 G.C.

\begin{tabular}{|c|c|c|c|}
\hline Explanatory variables & Category & Case & Control \\
\hline \multirow{2}{*}{ Parity } & Unipara & 70 & 180 \\
\hline & Multipara & 61 & 83 \\
\hline \multirow{2}{*}{ Presclampsia } & Yes & 6 & 2 \\
\hline & No & 125 & 261 \\
\hline \multirow{2}{*}{ Eclampsia } & Yes & 2 & 0 \\
\hline & No & 129 & 263 \\
\hline \multirow{2}{*}{$\mathrm{APH}$} & Yes & 2 & 0 \\
\hline & No & 129 & 263 \\
\hline \multirow{2}{*}{ ANC Utilization } & Yes & 101 & 203 \\
\hline & No & 28 & 61 \\
\hline \multirow{4}{*}{ Number of ANC Visit } & One visit only & 2 & 3 \\
\hline & Two vist only & 33 & 25 \\
\hline & Three visit only & 50 & 33 \\
\hline & Four and above vist & 18 & 100 \\
\hline \multirow{2}{*}{ Maternal MUAC } & $<23 \mathrm{~cm}$ & 69 & 94 \\
\hline & $\geq 23 \mathrm{~cm}$ & 61 & 166 \\
\hline \multirow{2}{*}{ Marernal Stature } & $<150 \mathrm{~cm}$ & 7 & 11 \\
\hline & $>150 \mathrm{~cm}$ & 115 & 250 \\
\hline
\end{tabular}

(95\% CI $=1.21-3.96)$. in this study nutritional status of the mother were assessed through MUAC and the finding revealed that the risk of giving LBW baby among mothers who had MUAC less than $23 \mathrm{~cm}$ was 2 times higher compared to mother with MUAC greater than $23 \mathrm{~cm}$. (AOR $1.79(95 \% \mathrm{CI}=1.01-3.16)$ ) (Table 4).

\section{Discussion}

This study tries to elucidate the determinates of low birth weight among new born delivered in public hospitals of Gurage zone. The result indicated that gestational age, multiple pregnancy, malaria infection during pregnancy, maternal undernutrition and mulitparity were a significant predictors of LBW.

Comparing to term birth, Those new born delivered before 37 weeks of gestation had about 24 times higher risk to LBW. This might be due to the fact that, before 37 weeks of gestational age fetal growth and development couldn't be completed. Hence, the fetus may not gain adequate weight during its birth. This finding is inline with study done in Tigray region of Ethiopia, north east Iran and Nepal [14] [17] [18].

The other factor that independently linked with LBW was multiple pregnancy particularly twin pregnancy. Comparing to singlton, twins had about five times higher chance of having LBW. This may be due to nutritional share in vitro. 
Table 4. Factors associated with LBW from logistic regression analysis, southern Ethiopia, Gurage zone, 2017 G.C.

\begin{tabular}{|c|c|c|c|c|c|}
\hline Variables & Category & Case & Control & COR $(95 \% \mathrm{CI})$ & $\operatorname{AOR}(95 \% \mathrm{CI})$ \\
\hline \multirow{2}{*}{ Gestational age } & $<37$ weeks & 74 & 14 & $23.28(12.28-44.12)$ & AOR $24.94(12.38-50.27)$ \\
\hline & $\geq 37$ weeks & 57 & 251 & 1.00 & 1.00 \\
\hline \multirow{2}{*}{ Twining } & Singleton & 23 & 9 & 1.00 & 1.00 \\
\hline & Twin & 108 & 254 & $6.01(2.69-13.41)$ & $5.42(2.01-14.59)$ \\
\hline \multirow{2}{*}{ MUAC } & $<23 \mathrm{~cm}$ & 69 & 94 & $1.99(1.30-3.06)$ & $1.790(1.01-3.16)$ \\
\hline & $\geq 23 \mathrm{~cm}$ & 61 & 166 & 1.00 & 1.00 \\
\hline \multirow{2}{*}{ Parity } & Uni-para & 70 & 180 & 1.00 & 1.00 \\
\hline & Multi-para & 61 & 83 & $1.89(1.23-2.09)$ & $2.19(1.21-3.96)$ \\
\hline \multirow{2}{*}{$\begin{array}{c}\text { Presence of } \\
\text { Preeclampsia }\end{array}$} & Yes & 6 & 5 & $6.26(1.24-31.48)$ & $3.19(0.33-31.25)$ \\
\hline & No & 125 & 261 & 1.00 & 1.00 \\
\hline \multirow{2}{*}{$\begin{array}{c}\text { Presence of } \\
\text { Malaria Infection }\end{array}$} & Yes & 28 & 24 & $2.72(1.50-4.91)$ & AOR $3.018(1.39-6.51)$ \\
\hline & No & 103 & 240 & 1.00 & 1.00 \\
\hline \multirow{2}{*}{ Sex } & Male & 68 & 159 & 1.00 & $0.636(0.36-1.12)$ \\
\hline & Female & 63 & 105 & $1.40(0.92-2.14)$ & 1.00 \\
\hline \multirow{2}{*}{ Residence } & Urban & 68 & 115 & $1.41(0.92-2.14)$ & $0.89(0.49-1.60)$ \\
\hline & Rural & 63 & 150 & 1.00 & 1.00 \\
\hline
\end{tabular}

This investigation also indicated that Maternal nutritional status during pregnancy independently associated LBW. Those mothers with MUAC less than 23 $\mathrm{cm}$ had higher chance to have LBW baby. This recognized fact is due to compromization of nutrient supply to the developing fetus. Comparing to other studies finding, this find in is very consistent with study done in South-East Ethiopia [16].

In this study Malaria found to be significant predictors of LBW. The chance of LBW amog mothers who had malaria infection during their pregnancy period was three times higher than malaria free mothers. This strong relationship is may be due to the fact that malaria infection during pregnancy couse asphyxia four the fetus, maternal animia and ultimately interutrine growth restriction. Studies done in Bale zone hospitals, South-East Ethiopia highly supports this findings [16].

Since mass of cases and control participants didn't face complication during their pregnancy and delivery, Obstetrical complication like preeclampsia, eclampsia, APH, didn't show statistically significant association with LBW.

In addition, the proportion congenital and placental anomalies in all study subjects (in case and control) were similar this study variable didn't show a significant association with low birth weight.

This study had some strength. Because the finding of this study was based a prospective case control study, it could give us a more strong evidence on causa- 
tion compared to cross-sectional and other descriptive study. Besides, to identify the existing difference, study populations were selected by using probability sampling technique. To minimize the selection bias, clear case definitions, inclusion and exclusion criteria and standard measurement instruments were used. For minimizing information bias, the questionnaire was prepared in the form of closed ended question; to have heartfelt response from respondent intensive training was given for the data collectors and supervisor; pretest was done for assuring applicability of the questionnaire in the study area. This study also had some limitation. Because presence of malaria was determined through maternal history recall bias may be introduced during period of data collection.

\section{Conclusion}

To this study, gestational age $<37$ weeks, twining, malaria infection during pregnancy and maternal undernutrition were significant predictors of LBW in the region of Gurage zone. Hence this study implicated that to effectively prevent low birth weight, Gurage zone health departments should promote on enhancement of maternal nutritional status and prevent malaria during pregnancy.

\section{Acknowledgements}

This research work couldn't have been completed without cooperation of Gurage Zone Health department. Besides, we are very happy to express our deepest gratitude to the data collectors and study participants, because without their participation this study wouldn't be realized.

\section{Conflicts of Interest}

The authors declare no conflicts of interest regarding the publication of this paper.

\section{References}

[1] Gülmezoglu, M., de Onis, M. and Villar, J. (1997) Effectiveness of Interventions to Prevent or Treat Impaired Fetal Growth. Obstetrical and Gynecological Survey, 52, 139-149.

[2] ACC/SCN (2000) Fourth Report on the World Nutrition Situation. ACC/SCN in Collaboration with IFPRI, Geneva.

[3] Barker, D.J.P. (1998) Mothers, Babies and Health in Adult Life. Churchill Livingstone, Edinburgh.

[4] Risnes, K.R., Vatten, L.J., Baker, J.L., Jameson, K., Sovio, U., Kajantie, E., et al. (2011) Birthweight and Mortality in Adulthood: A Systematic Review and Metaanalysis. International Journal of Epidemiology, 40, 647-661. https://doi.org/10.1093/ije/dyq267

[5] Goldenberg, R.L., Culhane, J.F., Iams, J.D. and Romero, R. (2008) Epidemiology and Causes of Preterm Birth. The Lancet, 371, 75-84. https://doi.org/10.1016/S0140-6736(08)60074-4

[6] Kramer, M.S., Papageorghiou, A., Culhane, J., Bhutta, Z., Goldenberg, R.L., Gravett, M., et al. (2012) Challenges in Defining and Calssifying the Preterm Birth Syndrome. American Journal of Obstetrics \& Gynecology, 206, 108-112. 
https://doi.org/10.1016/j.ajog.2011.10.864

[7] Goldenberg, R.L., Gravett, M.G., Iams, J., Papageorghiou, A.T., Waller, S.A., Kramer, M., et al. (2012) The Preterm Birth Syndrome: Issues to Consider in Creating a Classification System. American Journal of Obstetrics \& Gynecology, 206, 113-118. https://doi.org/10.1016/j.ajog.2011.10.865

[8] Villar, J., Papageorghiou, A.T., Knight, H.E., Gravett, M.G., Iams, J., Waller, S.A., et al. (2011) The Preterm Birth Syndrome: A Prototype Phenotypic Classification. American Journal of Obstetrics \& Gynecology, 206, 119-123. https://doi.org/10.1016/j.ajog.2011.10.866

[9] Larroque, B., Bertrais, S., Czernichow, P. and Leger, J. (2001) School Difficulties in 20-Year Olds Who Were Born Small for Gestational Age at Term in a Regional Cohort Study. Pediatrics, 108, 111-115. https://doi.org/10.1542/peds.108.1.111

[10] Kim, D. and Saada, A. (2013) The Social Determinants of Infant Mortality and Birth Outcomes in Western Developed Nations: A Cross-Country Systematic Review. International Journal of Environmental Research and Public Health, 10, 2296-335.

[11] Muglia, L.J. and Katz, M. (2010) The Enigma of Spontaneous Preterm Birth. The New England Journal of Medicine, 362, 529-535. https://doi.org/10.1056/NEJMra0904308

[12] (2012) WHA Global Nutrition Targets 2025: Low Birth Weight Policy Brief.

[13] Meresa Gebremedhin, F.A., Admassu, E. and Berhane, H. (2015) Maternal Associated Factors of Low Birth Weight: A Hospital Based Cross-Sectional Mixed Study in Tigray, Northern Ethiopia. BMC Pregnancy and Childbirth, 15, 222. https://doi.org/10.1186/s12884-015-0658-1

[14] Carmelo, G.A., Nobile, G.R., Altomare, C. and Pavia, M. (2007) Influence of Maternal and Social Factors as Predictors of Low Birth Weight in Italy. BMC Public Health, 7, 192. https://doi.org/10.1186/1471-2458-7-192

[15] Habtamu Demelash, A.M., Nigatu, D., Gashaw, K. and Melese, A. (2007) Risk Factors for Low Birth Weight in Bale Zone Hospitals, South-East Ethiopia: A Case-Control Study. BMC Public Health, 15, 264.

[16] Negassi Teklehaimanot, T.H. and Assefa, H. (2014) Prevalence and Factors Associated with Low Birth Weight in Axum and Laelay Maichew Districts, North Ethiopia: A Comparative Cross Sectional Study. Science, 3, 560-566.

[17] Chaman, R., et al. (2013) Low Birth Weight and Its Related Risk Factors in Northeast Iran. Iranian Journal of Pediatrics, 23, 701-704.

[18] Sharma, S.R., Giri, S., Timalsina, U., et al. (2015) Low Birth Weight at Term and Its Determinants in a Tertiary Hospital of Nepal: A Case-Control Study. PLoS ONE, 10, e0123962. https://doi.org/10.1371/journal.pone.0123962 